\title{
Tremolite Asbestos
}

National Cancer Institute

\section{Source}

National Cancer Institute. Tremolite Asbestos. NCI Thesaurus. Code C45530.

A naturally occurring, grayish, fibrous amphibole asbestos mineral and occurs as a contaminant in chrysotile asbestos. Chronic inhalation of its dust may cause asbestosis and increases the risk of respiratory tract cancer, mesothelioma and other lung cancers.

Tremolite Asbestos is a known human carcinogen. ( $\mathrm{NCl05)}$ 